\title{
Levantamento taxonômico das Chlorophyta (Volvocales, Chlorococcales, Zygnematales) do Reservatório da Pampulha, MG
}

\author{
PAULA CABRAL ETEROVICK ${ }^{1}$ e ALESSANDRA GIANI ${ }^{1}$
}

(recebido em 22/06/95; aceito em 04/12/96)

\begin{abstract}
Taxonomic survey of Chlorophyta (Volvocales, Chlorococcales, Zygnematales) from Pampulha Reservoir, MG). A taxonomic survey of planktonic Chlorophyta (Volvocales, Chlorococcales, Zygnematales) was performed in the Pampulha Reservoir (Minas Gerais, Brazil). Samples were collected monthly, from May 1992 to August 1994. Thirty-six species were identified belong to the orders Chlorococcales, Volvocales and Zygnematales. Chlorococcales was represented by the largest number of species (27 species in nine families), followed by Zygnematales (eight species in one family) and by Volvocales, with a single species. Most of the described species $(70 \%)$ are a first citation for Minas Gerais state.
\end{abstract}

RESUMO - (Levantamento taxonômico das Chlorophyta (Volvocales, Chlorococcales, Zygnematales) do Reservatório da Pampulha, MG). Foi realizado um levantamento taxonômico das Chlorophyta planctônicas (Volvocales, Chlorococcales, Zygnematales) no Reservatório da Pampulha (Minas Gerais, Brasil). As amostras foram coletadas mensalmente, de maio de 1992 a agosto de 1994. Foram encontradas 36 espécies pertencentes às ordens Chlorococcales, Volvocales e Zygnematales. A ordem Chlorococcales foi a que apresentou maior número de espécies (27 espécies distribuídas em nove famílias), seguida de Zygnematales (oito espécies em uma família) e de Volvocales (uma espécie). A maioria destas espécies (70\%) é citada pela primeira vez para o estado de Minas Gerais.

Key words - Taxonomy, eutrophic reservoir, Chlorophyta

\section{Introdução}

São raros os estudos taxonômicos de fitoplâncton no estado de Minas Gerais. Um dos primeiros trabalhos foi realizado por Nordstedt (1877) sobre desmidiáceas. A maior parte da bibliografia disponível é muito antiga, publicada por autores estrangeiros (Boergesen 1890, Warming 1892, Borge 1899, Förster 1964). Rennó (1958) realizou o primeiro estudo relativo ao fitoplâncton no Reservatório da Pampulha, limitando-se, porém, à citação de gêneros (Anabaena, Arthrodesmus, Chlamydomonas, Closterium, Cosmarium, Pediastrum, Peridinium, Planktosphaeria, Scenedesmus e Staurastrum) que ainda são encontrados na lagoa.

A Lagoa da Pampulha é um reservatório periurbano localizado no município de Belo Horizonte. É considerada um dos sistemas lacustres mais bem estudados no estado de Minas Gerais (Pinto-Coelho 1992). Embora estudos limnológicos ali desenvolvidos tenham dado origem a diversos trabalhos e artigos científicos, até o momento nenhuma publicação foi feita sobre o inventário

1. Departamento de Botânica, Instituto de Ciências Biológicas, Universidade Federal de Minas Gerais, Caixa Postal 486, 31270-110 Belo Horizonte, MG, Brasil. taxonômico das espécies de algas planctônicas da represa.

O Reservatório da Pampulha encontra-se em estágio avançado de eutrofia, processo que vem se agravando nas últimas décadas. A degradação da qualidade da água tem causado alterações na comunidade biológica, provocando o desaparecimento de certas espécies e o surgimento de outras (Pinto-Coelho 1992, Giani 1994).

O objetivo deste trabalho é aumentar o conhecimento, tão escasso, da ficoflórula do estado de Minas Gerais, apresentando um inventário das algas verdes (Chlorophyta) planctônicas do Reservatório da Pampulha e, desta forma, dar suporte aos inúmeros estudos limnológicos que vêm sendo realizados nesta represa.

\section{Material e métodos}

O Reservatório da Pampulha, inserido na Bacia Hidrográfica da Pampulha, localiza-se no município de Belo Horizonte, tendo sido formado artificialmente em 1938. Sua profundidade máxima é de $16 \mathrm{~m}$ e a profundidade média de $5 \mathrm{~m}$. Com um espelho d'água de $2,4 \mathrm{~km}^{2}$ e um volume de $12 \times 10^{9} \mathrm{dm}^{3}$, constitui hoje um dos principais acervos turísticos dessa capital. A região caracteriza-se por duas estações climáticas distintas: uma seca (de maio a outubro) e uma chuvosa, que coincide com o verão, estendendo-se normalmente de novembro a abril (Giani et al. 1988).

As amostras foram coletadas, mensalmente, com redes de plâncton de malha de $20 \mu \mathrm{m}$ e $60 \mu \mathrm{m}$ de poro, para identificação das espécies presentes, no período de maio de 1992 a agosto de 1994. As coletas foram realizadas em estação única, próxima à 
Igreja da Pampulha, localizada na margem sul do reservatório. Todas as amostras foram fixadas em lugol acético e armazenadas em frascos de vidro, abrigadas da luz.

Os gêneros e os níveis hierárquicos superiores foram identificados de acordo com Bourrelly (1972). A identificação das espécies foi feita de acordo com Smith (1920), Teiling (1967), Prescott et al. (1981, 1982), Komárek \& Fott (1983), Sant’Anna (1984), Castro (1987), Korshikov (1987), Nogueira (1991) e De-Lamonica-Freire \& Sant'Anna (1993). As amostras examinadas encontram-se depositadas no herbário do Departamento de Botânica da Universidade Federal de Minas Gerais (BHCB). Para este trabalho, foram selecionadas apenas seis dentre as amostras herborizadas, as quais continham todos os táxons identificados.

\section{Resultados e Discussão}

Foram identificados 36 táxons infragenéricos dentro da divisão Chlorophyta no período de 1992 a 1994. A ordem Chlorococcales foi a que apresentou maior número de espécies (27, uma delas com duas subespécies), distribuídas em nove famílias: Chlorococcaceae (2), Coccomixaceae (2), Dictyosphaeriaceae (1), Hydrodictyaceae (1), Micractiniaceae (2), Oocystaceae (7), Palmellaceae (1), Radiococcaceae (1) e Scenedesmaceae (10). Na ordem Zygnematales todas as espécies encontradas (8) pertencem à família Desmidiaceae. Na ordem Volvocales, família Chlamydomonadaceae, observou-se apenas uma espécie de Chlamydomonas .

A seguir encontram-se as descrições dos táxons identificados. Para as medidas das células, usaram-se as seguintes abreviações: D (diâmetro), C (comprimento), L (largura), E (espessura), i (istmo), ssp (sem espinhos), csp (com espinhos), spr (sem processos), cpr (com processos).

\section{VOLVOCALES}

Chlamydomonadaceae

Chlamydomonas sp.

Figura 1.

Células solitárias, livres, esféricas; cloroplasto com pirenóide presente; mancha ocelar presente, pequena, no terço inferior da célula; dois flagelos iguais, ligeiramente mais longos que a célula. Células D 13,4-23,9 $\mu \mathrm{m}$.

Comentários - Chlamydomonas sp. não pôde ser identificada ao nível de espécie devido ao método de fixação, que tornou o cloroplasto intensamente pigmentado, impossibilitando a observação de suas estruturas. Para uma melhor visualização dos cloroplastos, deveriam ser observados os indivíduos in vivo, embora não tenham sido muito abundantes no Reservatório da Pampulha neste período de estudo.

Material examinado - BHCB28569, BHCB28571, BHCB28574.

\section{CHLOROCOCCALES}

Chlorococcaceae

Planktosphaeria gelatinosa G.M. Smith

Figura 2.

Colônia com 1, 2 células, irregularmente distribuídas, envolvidas por um envelope de mucilagem hialino, homogêneo. Células esféricas; célula adulta com vários cloroplastos, parietais poligonais, achatados, cada um com 1 pirenóide Reprodução por colônias filhas. Liberação por ruptura do envelope de mucilagem. Células D 5,2-6,7 $\mu \mathrm{m}$.

Comentários - Planktosphaeria gelatinosa, no Reservatório da Pampulha, encontra-se com células de tamanho menor do que o citado na literatura.

Material examinado - BHCB28573.

Primeira citação da ocorrência da espécie no estado de Minas Gerais.

\section{Tetraedron minimum A. Braun}

Figura 3.

Células solitárias; vista frontal quadrangular, com ângulos arredondados e margens côncavas, vista lateral fusiforme elíptica; paredes lisas; cloroplasto único, parietal, com 1 pirenóide. Reprodução por formação de esporos. Liberação do esporos por ruptura ou dissolução da parede. Células L 8,0-13,4 $\mu \mathrm{m}$; E 3,0-6,7 $\mu \mathrm{m}$.

Material examinado - BHCB28571, BHCB28572. Distribuição geográfica no estado de Minas Gerais município de Belo Horizonte, Pampulha (Giani \& Leonardo 1988).

Tetraedron minimum A. Braun var. minimum Hansgirg

Figura 4.

Células solitárias, achatadas; vista frontal quadrangular, com ângulos arredondados e margens côncavas; parede celular lisa. Células L 6,7-8, $1 \mu \mathrm{m}$; E 3,2-4,2 $\mu \mathrm{m}$. 
Material examinado - BHCB28569.

Primeira citação da ocorrência da variedade no estado de Minas Gerais.

Coccomyxaceae

Elakatothrix acuta Pascher

Figuras 5-9.

Colônias com poucas células, irregularmente alinhadas, em mucilagem difluente. Células fusiformes, ápices levemente agudos; cloroplasto único, laminar, 1-2 pirenóides. Células C 13,5-17,8 $\mu \mathrm{m}$; L 3,3-5,3 $\mu \mathrm{m}$. Colônias C 17,6-43,8 $\mu \mathrm{m}$; L $8,0-12,3 \mu \mathrm{m}$.

Material examinado - BHCB28569, BHCB28571, BHCB28572, BHCB28573.

Primeira citação da ocorrência da espécie no estado de Minas Gerais.

\section{Elakatothrix americana Wille}

Figura 10.

Sinônimo: Elakatothrix gelatinosa Wille var. gelatinosa f. minus Philipose, Revta. brasil. Bot. 5:72, fig. 8, 1982.

Colônias fusiforme-alongadas a irregulares, eixo maior paralelo ao eixo maior das células, dispostas aos pares. Células lanceoladas, geralmente com um pólo truncado arredondado e o outro agudo, os lados truncados de um par de células em oposição; cloroplasto único, parietal, laminar, com 1 pirenóide. Células C 6,7-11,7 $\mu \mathrm{m}$; L 2,5-3,5 $\mu \mathrm{m}$. Colônias C 21,1-25,1 m; L 9,2-11,0 $\mu \mathrm{m}$.

Material examinado - BHCB28570, BHCB28572.

Primeira citação da ocorrência da espécie no estado de Minas Gerais.

Dictyosphaeriaceae

Dictyosphaerium pulchellum Wood

Figura 11.

Colônias esféricas ou ligeiramente ovóides, com 4-8-16-32 ou mais células na periferia de um envelope de mucilagem hialino e homogêneo, arranjadas de 4 em 4 nas terminações de ramificações mucilaginosas. Células adultas esféricas, células jovens esféricas a ovóides; cloroplasto único, parietal, poculiforme, com 1 pirenóide. Células D 3,3-5,8 $\mu \mathrm{m}$. Colônias D 29,2-51,3 $\mu \mathrm{m}$.
Material examinado - BHCB28569, BHCB28570, BHCB28571, BHCB28572, BHCB28573, BHCB28574.

Distribuição geográfica no estado de Minas Gerais: Brejo da Lapa, Parque Nacional de Itatiaia, RJ (Bicudo \& Ventrici 1968); município de Belo Horizonte, Pampulha (Giani \& Leonardo 1988).

Hydrodictyaceae

Pediastrum simplex Meyen var. simplex

Figura 12.

Cenóbios arredondados, 4-8-16 células dispostas concentricamente; numerosos espaços intercelulares, às vezes apenas um e amplo, raramente ausentes; células externas e internas poligonais, as externas com um processo cônico truncado, longo (1,6-1,7 vez a largura da célula); parede celular granulosa, denticulada, às vezes levemente pontuada; cloroplasto único, parietal, ocupando todo o processo, com 1 pirenóide.

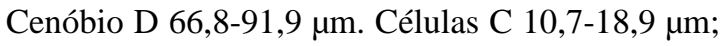
L 8,4-10,5 $\mu \mathrm{m}$.

Material examinado - BHCB28570.

Primeira citação da ocorrência da espécie no estado de Minas Gerais.

Micractiniaceae

Golenkinia radiata Chodat

Figura 13.

Células isoladas, esféricas; parede celular com setas longas, delicadas, hialinas; cloroplasto poculiforme, com 1 pirenóide reniforme. Células D 3,6-6,8 $\mu \mathrm{m}$. Setas C 30,0-72,0 $\mu \mathrm{m}$.

Comentários - As setas apresentam comprimento maior que o citado na literatura.

Material examinado - BHCB28572.

Primeira citação da ocorrência da espécie no estado de Minas Gerais.

Micractinium bornhemiense (Conrad) Korsikov Figura 14.

Colônias piramidais compostas de 16-64 células. Células esféricas; margem livre da parede celular com 1-2 setas longas, hialinas; cloroplasto poculiforme, com 1 pirenóide. Células D 2,8-11,7 $\mu \mathrm{m}$. Setas C 40,0-90,0 $\mu \mathrm{m}$.

Comentários - As setas apresentam comprimento igual a maior do que o citado na literatura. 
Material examinado - BHCB28572.

Primeira citação da ocorrência da espécie no estado de Minas Gerais.

Oocystaceae

Chlorella vulgaris Beyerinck

Figura 15.

Células solitárias ou, eventualmente, formando pequenos agregados, esféricas; parede celular lisa e delicada; cloroplasto parietal, poculiforme, com pirenóide conspícuo ou inconspícuo. Células D 3,3-6,8 $\mu \mathrm{m}$.

Material examinado - BHCB28569, BHCB28570, BHCB28571, BHCB28572, BHCB28573, BHCB28574.

Distribuição geográfica no estado de Minas Gerais: município de Belo Horizonte, Pampulha (Giani \& Leonardo 1988).

\section{Kirchneriella obesa (W. West) Schmidle}

Figura 19.

Colônias com 8-16-64 células, arranjadas irregularmente, mucilagem pouco evidente. Células lunadas, achatadas, com o lado externo marcadamente convexo e o lado interno côncavo, pólos arredondados ou levemente atenuados; cloroplasto único, com 1 pirenóide, preenchendo toda a célula, incisão mediana conspícua. Células L

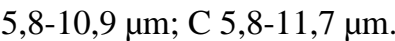

Material examinado - BHCB28569, BHCB28570, BHCB28571, BHCB28572.

Primeira citação da ocorrência da espécie no estado de Minas Gerais.

\section{Monoraphidium contortum (Thuret) \\ Komárková-Legnerová \\ Figura 16.}

Células isoladas, fusiforme-alongadas, helicoidais, com 1 a 1,5 volta, ápices gradualmente afilados; cloroplasto único, parietal, sem pirenóide; incisão nuclear conspícua. Reprodução por quatro autósporos seriados. Células C 13,4-20,0 $\mu \mathrm{m}$; L 0,8-2,6 $\mu \mathrm{m}$.

Material examinado - BHCB28570, BHCB28571

Primeira citação da ocorrência da espécie no estado de Minas Gerais.

\section{Monoraphidium minutum Nägeli}

Figura 17.

Células isoladas, lunadas, ápices arredondados, dispostos no mesmo plano; cloroplasto único, parietal, ocupando até o ápice, sem pirenóide; incisão nuclear conspícua. Reprodução por quatro autósporos seriados. Grau de curvatura das células

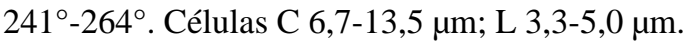

Material examinado - BHCB28571, BHCB28572.

Primeira citação da ocorrência da espécie no estado de Minas Gerais.

\section{Monoraphidium sp.}

Figura 18.

Células isoladas, fusiforme-alongadas, retas, 7,6 a 16 vezes mais longas que largas, ápices gradualmente afilados; cloroplasto único, parietal, sem pirenóide; incisão nuclear conspícua. Indivíduos em reprodução não observados. Células C 13,3-20,0 $\mu \mathrm{m}$; L 0,8-2,6 $\mu \mathrm{m}$.

Comentários - Monoraphidium sp. assemelha-se, em seu aspecto geral, a Monoraphidium griffithii (Berkeley) Komárková-Legnerová; porém, apresenta dimensões consideravelmente menores que as descritas para esta espécie.

Material examinado - BHCB28569, BHCB28570, BHCB28571, BHCB28572, BHCB28574.

Oocystis lacustris Chodat

Figuras 20-22.

Células isoladas ou em colônias de 2-4-8-16 indivíduos, irregularmente distribuídas em uma mucilagem. Células elípticas, pólos levemente pontiagudos, com ou sem nódulos polares; 1 a 4 cloroplastos parietais, sem pirenóide ou com pirenóide pouco conspícuo. Células C 3,0-13,4 $\mu \mathrm{m}$; L 2,5-8,4 $\mu \mathrm{m}$.

Material examinado - BHCB28569, BHCB28570, BHCB28571, BHCB28572, BНCB28573, BHCB28574.

Distribuição geográfica no estado de Minas Gerais município de Belo Horizonte (Giani \& Leonardo 1988).

Oocystis pusilla Hansgirg

Figura 23.

Colônias com 4-8 células irregularmente distribuídas em mucilagem. Células elípticas, pólos 

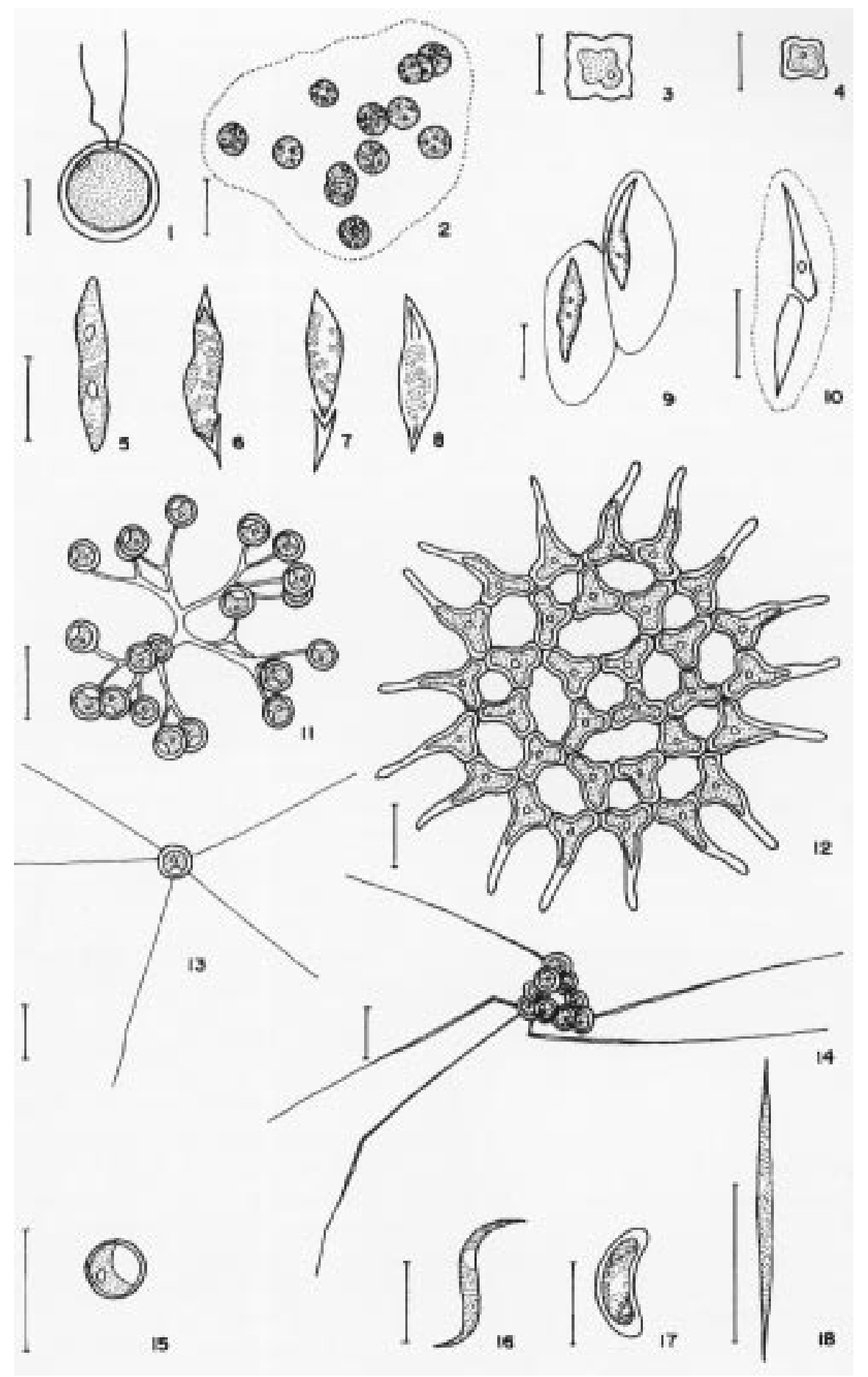

Figura 1. Chlamydomonas sp. Figura 2. Planktosphaeria gelatinosa. Figura 3. Tetraëdron minimum. Figura 4. Tetraëdron minimum var. minimum. Figuras 5-9. Elakatothrix acuta. Figura 10. Elakatothrix americana. Figura 11. Dictyosphaerium pulchellum. Figura 12. Pediastrum simplex var. simplex. Figura 13. Golenkinia radiata. Figura 14. Micractinium bornhemiense. Figura 15. Chlorella vulgaris. Figura 16. Monoraphidium contortum. Figura 17. Monoraphidium minutum. Figura 18. Monoraphidium sp. Escalas $=10 \mu \mathrm{m}$. 
arredondados e sem nódulos; cloroplasto único, parietal, com 1 pirenóide. Células C 5,0-9,2 $\mu \mathrm{m}$; L 3,7-5,1 $\mu \mathrm{m}$.

Material examinado - BHCB28569, BHCB28570.

Primeira citação da ocorrência da espécie no estado de Minas Gerais.

Palmellaceae

Eutetramorus planctonicus (Korsikov) Bourrelly

Figuras 24-26.

Colônias irregularmente alongadas, com numerosos grupos de 4-8 células, dispostas 2 a 2 em planos diferentes, em mucilagem hialina. Células esféricas; cloroplasto poculiforme, com 1 pirenóide. Células D 3,3- 7,5 $\mu \mathrm{m}$.

Material examinado - BHCB28569, BHCB28570, BHCB28571， BHCB28572， BHCB28573, BHCB28574.

Primeira citação da ocorrência da espécie no estado de Minas Gerais.

Radiococcaceae

Radiococcus planktonicus Lund

Figura 27.

Colônias arredondadas formadas por grupos de 4 células, irregularmente distribuídas em mucilagem, com bordas radialmente estriadas. Células esféricas; cloroplasto parietal, poculiforme, sem pirenóide. Células D 5,0-9,2 $\mu \mathrm{m}$.

Material examinado - BHCB28569.

Primeira citação da ocorrência da espécie no estado de Minas Gerais.

Scenedesmaceae

Coelastrum astroideum De Notaris

Figura 28.

Cenóbios esféricos com 16-32 células, espaços intercelulares quadrangulares e menores que o diâmetro celular. Células ovóides, sem processos mucilaginosos entre si; cloroplasto único, parietal, com 1 pirenóide. Células D 8,4-11,7 $\mu \mathrm{m}$. Colônias D 29,5-42,2 $\mu \mathrm{m}$.

Material examinado - BHCB28569, BHCB28571, BHCB28574.
Primeira citação da ocorrência da espécie no estado de Minas Gerais.

Coelastrum pseudomicroporum Korsikov

Figura 29.

Cenóbios esféricos com 16-32 células, espaços intercelulares aproximadamente triangulares. Células ovóides unindo-se às vizinhas através de 5-6 processos mucilaginosos curtos (menores que a metade do diâmetro celular), parede celular comprimida na região do contato. Células D 5,0-8,4 $\mu \mathrm{m}$. Colônias D 29,5-23,8 $\mu \mathrm{m}$.

Material examinado - BHCB28569, BHCB28570, BHCB28574

Distribuição geográfica no estado de Minas Gerais município de Belo Horizonte, Pampulha (Giani \& Leonardo 1988).

Crucigenia tetrapedia (Kirchner) W. \& G.S. West

Figura 30.

Cenóbios com 4 células, espaço retangular muito pequeno no centro do cenóbio. Células achatadas, triangulares, com ângulos arredondados; conteúdo celular homogêneo, com apenas um cloroplasto parietal, com 1 pirenóide. Células C 3,7-4,6 $\mu$ m; L 2,3-3,3 $\mu \mathrm{m}$. Cenóbios L 6,6-9,9 $\mu \mathrm{m}$.

Material examinado - BHCB28569, BHCB28570, BHCB28571， BHCB28572， ВНCB28573, BHCB28574.

Primeira citação da ocorrência da espécie no estado de Minas Gerais.

Crucigeniella rectangularis (Nägeli) Kom.

Figura 31.

Cenóbios com 4 células em contato mútuo nos lados internos e em um dos pólos, pequeno espaço retangular no centro do cenóbio. Células ovóides a ovóide-alongadas; 1 a 4 cloroplastos parietais disciformes, cada um com 1 pirenóide inconspícuo. Parede da célula-mãe freqüentemente envolve as células-filhas por algum tempo. Células C 3,0-5,8 $\mu \mathrm{m} ; \mathrm{L} 2,0-4,2 \mu \mathrm{m}$.

Material examinado - BHCB28569, BHCB28570, BHCB28571， BHCB28572， ВНCB28573, BHCB28574.

Primeira citação da ocorrência da espécie no estado de Minas Gerais. 
Scenedesmus bijugus (Turpin) Kützing var. disciformis (Chodat) Leite

Figura 32.

Sinônimo - Scenedesmus ecornis (Ralfs) Chodat var. disciformis Chodat.

Cenóbios planos com 4-8 células dispostas em duas fileiras superpostas. Células oblongo-elípticas, pólos arredondados; parede celular lisa; cloroplasto único, parietal, com 1 pirenóide. Células $\mathrm{C}$ 6,8-8,6 $\mu \mathrm{m} ; \mathrm{L} \mathrm{3,6-4,5} \mu \mathrm{m}$.

Material examinado - BHCB28574.

Primeira citação da ocorrência da espécie no estado de Minas Gerais.

\section{Scenedesmus brevispina (G.M. Smith) Chodat}

Figura 33.

Cenóbios planos com 4 células dispostas em série única. Células oblongas, 1 espinho curto em cada pólo; cloroplasto único, parietal, com 1 pirenóide. Células C 6,6-10,0 $\mu \mathrm{m} ; \mathrm{L}$ 2,3-3,4 $\mu \mathrm{m}$.

Material examinado - BHCB28569.

Primeira citação da ocorrência da espécie no estado de Minas Gerais.

\section{Scenedesmus denticulatus Lagerhein}

Figura 34.

Cenóbios planos, geralmente com 4 células dispostas alternadamente. Células ovóides a oblongas; 1-4 espinhos pequenos nos pólos; cloroplasto único, parietal, com 1 pirenóide. Células C 11,3-20,0 $\mu \mathrm{m}$; $\mathrm{L} 4,8-8,4 \mu \mathrm{m}$. Espinhos C 1,3-2,0 $\mu \mathrm{m}$.

Material examinado - BHCB28569.

Distribuição geográfica no estado de Minas Gerais Brejo da Lapa, Parque Nacional de ltatiaia, RJ (Bicudo \& Ventrici 1968); município de Belo Horizonte, Pampulha (Giani \& Leonardo 1988).

\section{Scenedesmus protuberans Fritsch \& Rich}

Figura 35.

Cenóbios retos com 2-4-8-16 células, dispostas linearmente. Células externas oblongas, pólos cônico-arredondados, curvos para fora, com 1 espinho de tamanho intermediário a longo (0,6-1,0 vez o comprimento celular), margem externa convexa; células internas oblongas; cloroplasto único, parietal com 1 pirenóide. Células C 13,4-20,0 $\mu \mathrm{m} ; \mathrm{L} 3,7-6,7 \mu \mathrm{m}$. Espinhos C 9,2-19,8 $\mu \mathrm{m}$.
Material examinado - BHCB28569, BHCB28570, BHCB28572, BHCB28574.

Primeira citação da ocorrência da espécie no estado de Minas Gerais.

Scenedesmus quadricauda (Turpin) Brebisson Figura 36.

Cenóbios planos com 2-4-8-16 células dispostas em série única linear ou subalternada. Células cilíndricas, pólos arredondados; pólos das células terminais com um espinho longo, reto ou curvo em cada um; células intermediárias sem espinhos. Células C 11,7-16,9 $\mu \mathrm{m} ; \mathrm{L} 4,2-5,8 \mu \mathrm{m}$. Espinhos C $10,0-10,4 \mu \mathrm{m}$.

Material examinado - BHCB28569.

Distribuição geográfica no estado de Minas Gerais município de Caldas, Fazenda Capivara (Nordstedt 1877); município de Belo Horizonte, Pampulha (Giani \& Leonardo 1988).

\section{Tetrastrum triangulare (Chodat) Komárek}

Figura 37.

Cenóbios planos, quadrangulares, com 4 células dispostas cruciadamente, espaço intercelular retangular, raramente ausente. Células subtriangulares, ângulos arredondados, margens externa e interna retas a levemente convexas; parede celular lisa; cloroplasto único, parietal, com 1 pirenóide inconspícuo. Reprodução por autósporos organizados em 4 cenóbios-filhos dispostos nas células-mãe, paralelamente ao cenóbio-mãe. Células C 2,2-3,3 $\mu \mathrm{m} ; \mathrm{L}$ 1,8-3,2 $\mu \mathrm{m}$. Cenóbios L $5,8-7,9 \mu \mathrm{m}$.

Material examinado - BHCB28569, BHCB28570, BHCB28571， BHCB28572， ВНCB28573, BHCB28574.

Primeira citação da espécie para o estado de Minas Gerais.

\section{ZYGNEMATALES}

Desmidiaceae

Closterium gracile Brébisson ex Ralfs var. gracile

Figura 39.

Células 23-31 vezes mais longas que largas, delgadas, quase retas por cerca de metade do comprimento, curvatura $25^{\circ}-40^{\circ}$ de arco, margens paralelas, afinando gradual e suavemente curvadas 


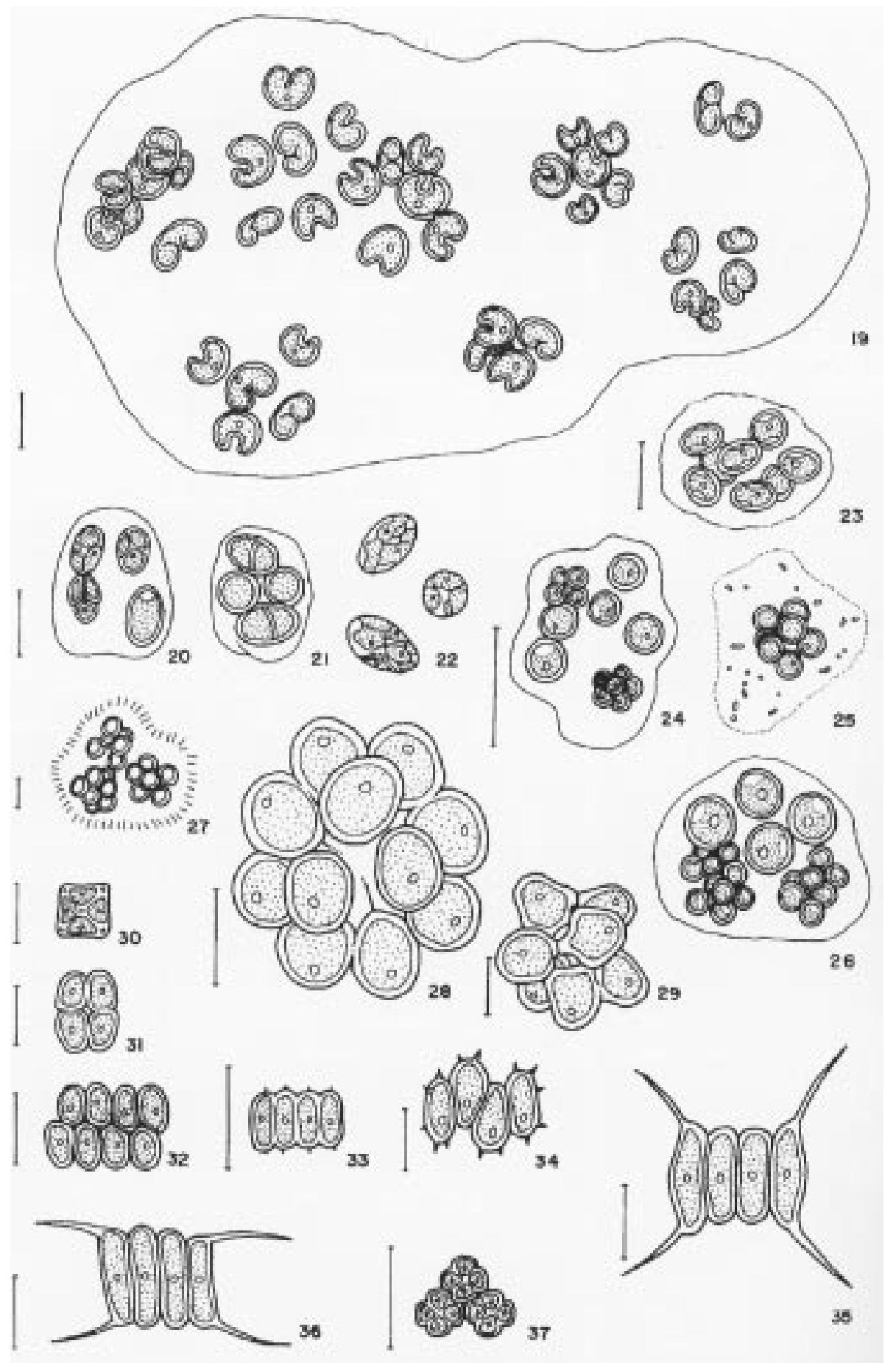

Figura 19. Kirchneriella obesa. Figuras 20-22. Oocystis lacustris. Figura 23. Oocystis pusilla. Figuras 24-26. Eutetramorus planctonicus. Figura 27. Radiococcus planktonicus. Figura 28. Coelastrum astroideum. Figura 29. Coelastrum pseudomicroporum. Figura 30. Crucigenia tetrapedia. Figura 31. Crucigeniella rectangularis. Figura 32. Scenedesmus bijugus var. disciformis. Figura 33. Scenedesmus brevispina. Figura 34. Scenedesmus denticulatus. Figura 35. Scenedesmus protuberans. Figura 36. Scenedesmus quadricauda. Figura 37. Tetrastrum triangulare. Escalas $=10 \mu \mathrm{m}$. 
em direção à região apical, pólos obtusos; parede celular lisa, incolor, faixas circulares às vezes evidentes; cloroplasto axial, 5-6 pirenóides em série mediana; vacúolos terminais com 1-5 grânulos. Células C 154,8-190,1 $\mu \mathrm{m}$; L 3,3-5,4 $\mu \mathrm{m}$.

Material examinado - BHCB28569, BHCB28572, HCB28574.

Distribuição geográfica no estado de Minas Gerais local não especificado na Fazenda Mãe D’água (Bicudo 1969).

Cosmarium polonicum var. polonicum Raciborski

Figura 40.

Células mais longas que largas, razão $\mathrm{C} / \mathrm{L}=$ 1,2-1,8; constrição mediana profunda, sinus linear e levemente dilatado no ápice; semicélulas reniformes, ângulos inferiores retangulares com um ápice agudo e denticulado, margens laterais ligeiramente convexas, convergindo para um ápice de mesma forma; margens das semicélulas crenuladas; parede celular com uma série de dentículos opondo-se às ondulações da margem, 2 ou 3 séries de grânulos arredondados, sendo a mais interna usualmente incompleta, com 3 grânulos menores horizontais logo acima do istmo e com 2 grânulos grandes e conspícuos na região média da célula; vista lateral da semicélula sub-hexagonal, porção inferior das margens laterais reta ou ligeiramente côncava, porção apical reta a ligeiramente retusa, ápice truncado; vista apical elíptica, com pólos granulados, margens laterais infladas na região mediana de cada lado, onde se localizam os 2 grânulos maiores. Células C

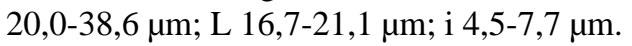

Material examinado - BHCB28571, BHCB28573, HCB28574.

Distribuição geográfica no estado de Minas Gerais município de Belo Horizonte (Giani \& Leonardo 1988).

Cosmarium subprotumidum var. gregorii (Roy et Biss.) West et West

Figura 41.

Células quase tão longas quanto largas, razão $\mathrm{C} / \mathrm{L}=1,2-1,7$; constrição mediana profunda, sinus linear com extremidade levemente dilatada; semicélulas trapeziformes com ângulos arredondados, largura máxima no terço inferior, sendo os 2/3 restantes estreitados em direção ao ápice, ângulos inferiores retangulares pouco arredondados, os setores convergentes superiores das margens laterais com duas concavidades e uma crista mediana, geralmente retusa, ápice truncado, com 2 ou 4 pequenas crenulações entre os ângulos apicais; parede celular com grânulos intramarginais arranjados mais ou menos em disposição radiada, geralmente em pares dentro de cada crena mas sozinhos longe das margens; vista lateral das semicélulas oval, com uma grande protuberância próxima à base, de cada lado; células elípticas em vista vertical, com uma protuberância proeminente 3 -granulada na região mediana. Células C

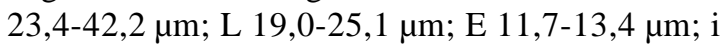
5,3-7,9 $\mu \mathrm{m}$.

Comentários - Esta variedade diferencia-se da típica pelas crenas acentuadamente bigranuladas, os grânulos marginais às vezes proeminentes e cônicos, os médios reduzidos, geralmente em três séries verticais com 3 ou 4 grânulos em cada fileira.

Material examinado - BHCB28569.

Primeira citação da ocorrência da espécie para o estado de Minas Gerais.

Cosmarium tinctum var. subretusum Messikommer

Figura 42.

Célula 1,2-1,3 vez mais longa que larga, levemente constricta; sinus abrindo amplamente; parede lisa ou finamente pontuada, incolor ou de coloração castanha; semicélulas oblongas em vistas apical e frontal, um pouco intumescidas em vista

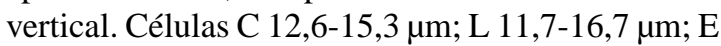
7,5-8,4 $\mu \mathrm{m}$; i 4,5-6,6 $\mu \mathrm{m}$.

Material examinado - BHCB28571, BHCB28572, BHCB28573.

Primeira citação da ocorrência da espécie no estado de Minas Gerais.

Staurastrum gracile var. coronulatum Boldt Figura 43.

Células cerca de 1,5 vez mais longas que largas sem os processos; constrição mediana pouco profunda, sinus como um entalhe em forma de " $U$ ", istmo relativamente largo; semicélulas trapezoidais, margem basal denticulada levemente convexa, divergindo diretamente para os ângulos apicais 
P.C. Eterovick e A. Giani: Chlorophyta do Reservatório da Pampulha

formando processos relativamente curtos, horizontais ou ligeiramente voltados para cima, providos de 4 dentes; margem apical larga, ligeiramente convexa ou quase reta; processos um pouco mais curtos que na variedade tipo, circundados por 5-7 séries concêntricas de grânulos; face das semicélulas apresentando grânulos concêntricos em torno dos processos; células triangulares em vista apical, com 2 verrugas emarginadas em cada margem lateral. Células $\mathrm{C}$ spr 29,04-31,68 $\mu \mathrm{m}$; L spr 11,7-18,4 $\mu \mathrm{m}$; C cpr

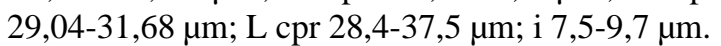
Material examinado - BHCB28569, ВНCB28570, BHCB28571, BHCB28572.

Distribuição geográfica no estado de Minas Gerais município de Lagoa Santa (Wille 1884, como Staurastrum gracile).

Staurastrum tetracerum (Kütz.) Ralfs var. tetracerum f. tetracerum

Figura 44.

Células tão longas quanto largas incluindo os processos, razão $\mathrm{C} / \mathrm{L}=1-1,1$; levemente torcidas, formando uma invaginação em forma de "V", sinus com um ápice sub-agudo; semicélulas triangulares, margens inferiores divergindo diretamente do sinus até os ângulos apicais, formando processos divergentes dirigidos para cima, margens dos processos serreadas, aparentemente ápice sem dentes; margem apical côncava; vista apical birradiada. Células C spr 6,7 -10,7

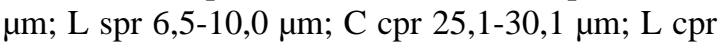
25,1-30,1 $\mu \mathrm{m}$; i 2,3-3,3 $\mu \mathrm{m}$.

Material examinado - BHCB28569.

Distribuição geográfica no estado de Minas Gerais - município de Lagoa Santa (Warming 1982, como Staurastrum tetracerum); município de Belo Horizonte, Pampulha (Giani \& Leonardo 1988, como Staurastrum tetracerum).

\footnotetext{
Staurastrum turgescens var. sparsigranulatum Scott et Grönblad

Figura 45.

Células mais longas que largas, razão $\mathrm{C} / \mathrm{L}=$ 1,3-1,4; constrição mediana profunda, sinus em forma de "V"; semicélulas elípticas, margem ventral mais convexa que a dorsal, ângulos laterais fortemente arredondados, margem apical claramente convexa; semicélulas triangulares em
}

vista apical, toda a margem granulada; face das semicélulas com numerosos grânulos, em número inferior e mais regularmente distribuídos que na variedade tipo. Célula C 19,5-22,3 $\mu \mathrm{m}$; L 14,3-16,8 $\mu \mathrm{m}$; i 7,8-8,8 $\mu \mathrm{m}$.

Material examinado - BHCB 28570, BHCB 28573, BHCB 28574.

Primeira citação da ocorrência da espécie no estado de Minas Gerais.

Staurodesmus convergens var. laportei (Teiling) Bicudo 1972

Figura 38.

Células aproximadamente tão longas quanto largas, razão $\mathrm{C} / \mathrm{L}=1,1-1,3$; constrição mediana profunda, sinus linear logo abrindo-se largamente, com extremidade arredondada; semicélulas ovais, margens basais convexas, parede celular lisa; ângulos atenuados contendo um espinho curto ligeiramente projetado para baixo, originado da linha mediana das semicélulas; contorno do ápice com os espinhos formando um arco; célula elíptica em vista apical. Células C 26,7-35,3 $\mu \mathrm{m}$; L ssp

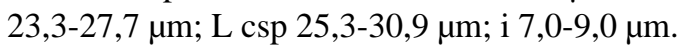
Material examinado - BHCB28569, BHCB28570, BHCB28571.

Primeira citação da ocorrência da espécie no estado de Minas Gerais.

Embora nenhuma espécie nova tenha sido encontrada no Reservatório da Pampulha, o fato de $70 \%$ dos táxons observados serem citações novas para o estado de Minas Gerais prova a necessidade de estudos desse tipo nesta região, tão rica em rios, lagos e reservatórios. Além disso, o impacto que muitos corpos d'água vêm sofrendo, no que se refere principalmente a dejetos orgânicos (esgotos domésticos, adubos) e industriais, tem causado alteração nas comunidades aquáticas existentes, provocando o desaparecimento de diversas espécies, que desta forma nunca chegaram a ser registradas neste estado.

Agradecimentos - À Dra. Maria Tereza P. Azevedo e à Dra. Célia Leite Sant'Anna, pelo auxílio na identificação de algumas espécies, ao Dr. Ricardo M. P. Coelho e aos seus estagiários, pela ajuda e apoio logístico no programa de coletas de campo, a Karen L. Goodwin, pela ajuda na coleta de material. O projeto foi parcialmente financiado pelo PRPq/UFMG através de bolsa de iniciacão científica a P.C.E. 


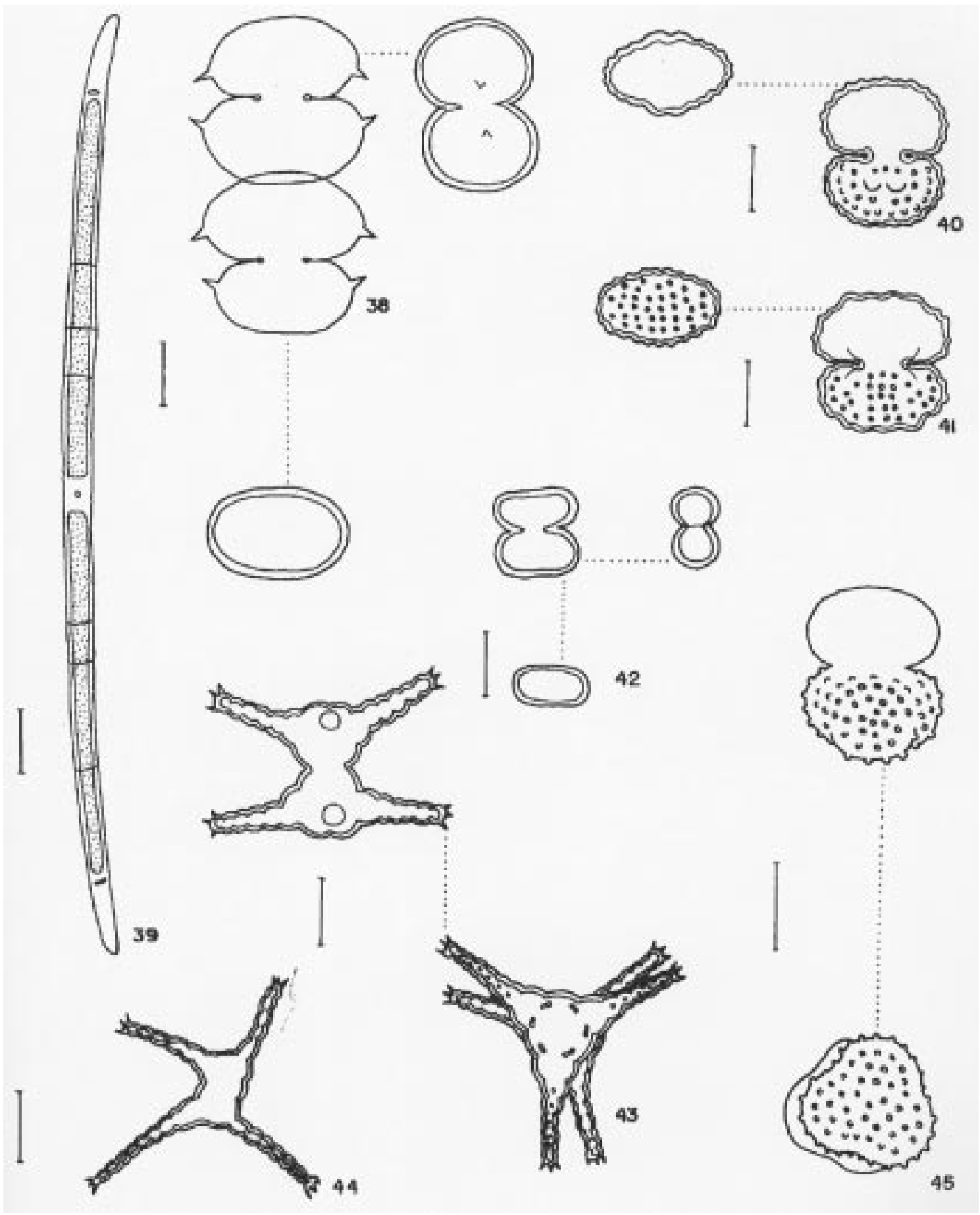

Figura 38. Staurodesmus convergens var. laportei. Figura 39. Closterium gracile. Figura 40. Cosmarium polonicum var. polonicum. Figura 41. Cosmarium subprotumidum var. gregorii. Figura 42. Cosmarium tinctum var. subretusum. Figura 43. Staurastrum gracile var. coronulatum. Figura 44. Staurastrum tetracerum var. tetracerum f. tetracerum. Figura 45. Staurastrum turgescens var. sparsigranulatum. Escalas $=10 \mu \mathrm{m}$. 


\section{Referências bibliográficas}

BICUDO, C.E.M. 1969. Contribution to the knowledge of the desmids of the State of São Paulo, Brazil. (Including a few from the State of Minas Gerais). Nova Hedwigia 17:433-569.

BICUDO, C.E.M. \& VENTRICE, M.R. 1968. Algas do Brejo da Lapa, Parque Nacional do Itatiaia, Brasil. In Anais do XIX Congresso da sociedade botânica do Brasil, p.-30.

BOERGESEN, F. 1890. Desmidiaceae Brasilieae, Symbolae ad Floram Brasiliae Centralis Congnoscendam. Vidensk. Medd. f. d. Naturh. Foren. part. 34:929-958.

BORGE, O. 1899. Über Tropische und Subtropische Süßwasser Chlorophyceen. Bih. Sv. K. Vet. - Akad. Handl. 24, Afd.3 (12):1-33.

BOURRELLY, P. 1972. Les algues d'eau douce, initiation à la sistemátique. Tome I: Les algues vertes. N. Boubée, Paris.

CASTRO, A.A.J. 1987. O gênero Closterium (Zygnemaphyceae) no estado de São Paulo: levantamento florístico. Dissertação de mestrado, Universidade Estadual Paulista, Rio Claro.

DE-LAMONICA-FREIRE, E.M. \& SANT' ANNA, C.L. 1993. Chlorococcales (Chlorophyceae) da Estação Ecológica da Ilha de Taiamã, estado de Mato Grosso, Brasil. Hoehnea 20:107-118.

FÖRSTER, K. 1964. Desmidiaceen aus Brasilien 2. Teil. Bahia, Goyaz, Piauhy und Nord-Brasilien. Hydrobiologia 23:321-505.

GIANI, A. 1994. Limnology in Pampulha Reservoir some general observations with emphasis on the phytoplankton community. In Ecology and human impact on lakes and reservoirs in Minas Gerais (R.M. Pinto-Coelho, A. Giani \& E. Von Sperling, eds). SEGRAC, Belo Horizonte, p.151-163.

GIANI, A \& LEONARDO, J.M. 1988. Distribuição vertical de algas fitoplanctônicas no Reservatório da Pampulha, Belo Horizonte, MG. Acta. Limnol. Brasil. 2:387-404.

GIANI, A., PINTO-COELHO, R.M., OLIVEIRA, S.J.M. \& PELLI, A. 1988. Ciclo sazonal de parâmetros físico-químicos da água e distribuição horizontal de nitrogênio e fósforo no reservatório da Pampulha (Belo Horizonte, MG, Brasil). Ciência e Cultura 40:69-77.

KOMÁREK, J. \& FOTT, B. 1983. Chlorophyceae (Grünalgen). Chlorococcales. In Das Phytoplankton des Süßwassers. Systematik und Biologie (Huber-Pestalozzi, ed.). E. Schweiserbart'sche Verlagsbuchandlung, v. 7(1): 1-1044.
KORSHIKOV, O.A. 1987. The freshwater algae of the Ukrainian ssr. V Sub class Protococcineae - Vacuolales and Protococcales. Bishen Singh Mahendra Pal Singh and Koeltz Scientific Books.

NOGUEIRA, I.S. 1991. Chlorococcales sensu lato (Chlorophyceae) do Município do Rio de Janeiro e arredores, Brasil. Inventário e considerações taxonômicas. Dissertação de mestrado, Universidade Federal do Rio de Janeiro, Rio de Janeiro.

NORDSTEDT, C.F.O. 1877. Nonnulae Aquae Dulcis Brasiliensis, Öfversigf af Kongl. Vetenskaps-Skademiens Förhandlingar, Stockholm 3:15-28.

PINTO-COELHO, R.M. 1992. Evolução do grau de eutrofização na Lagoa da Pampulha: comparação de ciclos sazonais de nutrientes ( $\mathrm{N}$ e $\mathrm{P}$ ) e organismos planctônicos. In Anais do Seminário da bacia hidrográfica da Pampulha. SEGRAC, Belo Horizonte, p.1-14.

PRESCOTT, G.W., CROASDALE, H.T., VINYARD, W. C. \& BICUDO, C.E.M. 1981. A Synopsis of North American Desmids. Part II Desmidiaceae: Placodermae. Section 3. University of Nebraska Press, Lincoln.

PRESCOTT, G.W.,BICUDO, C.E.M. \& VINYARD, W.C. 1982. A Synopsis of North American Desmids. Part II Desmidiaceae. Placodermae. Section 4. University of Nebraska Press, Lincoln.

RENNÓ, L.R. 1958. Aspectos fitolimnéticos da represa da Pampulha. Bolm. Agric. Dep. Prod. Veg. Belo Horiz. (Belo Horizonte) 7:11-48.

SANT' ANNA, C.L. 1984. Chlorococcales (Chlorophyceae) do estado de São Paulo, Brasil. Cramer, Vaduz. Biblioteca Phycologica n.67.

SMITH, G.M. 1920. Phytoplankton of the inland lakes of Wiscosin Part I: Mixophyceae, Phaeophyceae, Heterokantae and Chlorophyceae, exclusive of the Desmidiaceae. Wis. Ged. Nat. Hist. Serv. Bull. 57:1-243.

TEILING, E. 1967. The desmid genus Staurodesmus. A taxonomic study. Almqvist \& Wiksell, Stockholm.

W ARMING, E. 1892. Lagoa Santa, Et Bidrag til den Biologiske Plant geografi. K. Danske. Vidensk. Selsk. Skr (Kjobenhavn) 6, nat-math 6:153-488.

WILLE, N. 1884. Bidrag til Sydamericas algflora. I: Brasilien. Öfvers. K. Vetenk-Akad. Förn (Stockholm) 8:3-26. 